\title{
Kinetics and Isotherm studies of Lead (II) ion adsorption onto Pentapetes Phoenicea bio mass activated carbon
}

\author{
Galla Naga Hima Bindu ${ }^{1 *}$, Dr. T. Raja Rajeswari ${ }^{2}$ \\ ${ }^{1 *}$ Research Scholar, Dept. of Chemistry, Acharya Nagarjuna University, A.P \\ ${ }^{2}$ Reader in Chemistry, Y.A. Govt. College for Women, Chirala. A.P \\ *Email: kvsghb2122@gmail.com
}

\begin{abstract}
The current research aimed to use activated carbon (AC) obtained from Pentapetes Phoenicea biomass as an adsorbent material with high surface area developed through chemical activation with $0.5 \mathrm{MZnCl}_{2}$ followed by chemical activation with nitric acid. Porosity characterization of AC sample was done by using $\mathrm{N}_{2}$ adsorption and desorption experiments, surface area calculated by BET isotherm and found to be $324.651 \mathrm{~m}^{2} / \mathrm{g}$. Surface morphology and chemical elemental composition of prepared carbon adsorbent was evaluated by XRD, SEM-EDX, FT-IR and XPS techniques. It was found to have rough surface with porous structure and also depicts the presence of variety of surface functional groups. Porous activated carbon constituting larger proportion of mesopores gave higher adsorption capacity than that of microporous carbon with the dispersiveforce attraction being the dominant adsorption mechanism. Batch mode adsorption experiments were carried out to test the ability of prepared AC sample for the removal of Lead (II) ion from aqueous media (synthetic lead sample) at laboratory scale. The Langmuir and Freundlich adsorption isotherms were used to verify the adsorption performance. The obtained correlation coefficient $\left(\mathrm{R}^{2}=0.986\right)$ suggested best fitting of the experimental data to Freundlich Isotherm. $\mathrm{Pb}$ (II) ion showed the highest removal percentages by activated carbon at different concentrations and the removal percentages decreased as the concentration of $\mathrm{Pb}$ (II) ion increased. Adsorption kinetics of batch adsorption experiments was well described by the pseudo-second order model $\left(R^{2}=0.97\right)$ and the time to reach equilibrium was relatively long, suggesting the intra-particle diffusion to be the controlling step. High efficiency in $\mathrm{Pb}(\mathrm{II})$ removal indicates that activated carbon sample based on Pentapetes Phoenicea could be successfully used as an excellent adsorbent in water purification.
\end{abstract}

Index Terms- Activated carbon, Pentapetes Phoenicea biomass, Surface characterization, Batch adsorption, Isotherm study, Kinetics study.

\section{INTRODUCTION}

Heavy metal ion contamination of drinking/wastewater, especially with metal ions [1] such as $\mathrm{Pb}^{2+}, \mathrm{Cd}^{2+}, \mathrm{Cu}^{2+}, \mathrm{Ni}^{2+}$ and $\mathrm{Zn}^{2+}$ is a serious and ongoing problem. Among heavy metals, lead is one of the most widely distributed and largely found in aqueous wastes. Lead is a pollutant that is presents both in drinking water and industrial wastes [2]. Lead poisoning can cause hypertension, nausea, vomiting, etc [3]. Lead (II) ion $\left(\mathrm{Pb}^{2+}\right)$ concentration approach $200-500 \mathrm{mg} / \mathrm{L}$ in many types of waters, but as per WHO this value should be limited to a range of 0.01$0.05 \mathrm{mg} / \mathrm{L}$ [4].

Many technologies like adsorption, precipitation, membrane filtration, and ion-exchange have been used to remove metal pollutants like lead (II) from water [5]. However, batch adsorption has proven to be economical and efficient for removing removal polluted waters [6]. The uses of carbonaceous sorbents for heavy metal removal from various matrices via adsorption were the subjects of a number of research papers [7].

Activated carbon (AC) is widely utilised in adsorptive of pollutants that may be present in water and wastewater because its structure is highly microporous and it has high porosity and internal surface area [8]. Several studies in recent years have aimed to produce more efficient materials that have lower costs and widely available [9]. Several researchers used new method to prepare AC using a physicochemical activation process, which is a combined physical with chemical method. Pore development step of this method is carried out using both of the previously described activation procedures. Physico-chemically prepared AC obtained a higher surface area compared with physically or chemically prepared ones [10]. A careful search of the leading literature resources [11] yields a large number of biomaterial based activated carbons [12] being experimented as heavy metal (including Lead (II) ion) 


\section{E-ISSN: 2321-9637 \\ Available online at www.ijrat.org}

scavengers [13].There have been several reports [1415] that agricultural biomass [16] can be converted into activated carbon and used to absorb Lead (II) ions using $\mathrm{ZnCl}_{2}$ as the activating agent [17-18].

Kinetics is the study of the rates of chemical processes to understand the factors that influence the rates. Study of chemical kinetics includes careful monitoring of the experimental conditions which influence the speed of a chemical reaction and hence, help attain equilibrium in a reasonable length of time. Such studies yield information about the possible mechanism of adsorption and the different transition states on the way to the formation of the final adsorbate-adsorbent complex and help develop appropriate mathematical models to describe the interactions. The rates at which metal ions are transferred from the bulk solution to the adsorbent surface and are accumulated there determine the kinetics of adsorption and hence, the efficiency of the adsorption process. The study of kinetics provides an insight into the possible mechanism of adsorption along with the reaction pathways [19]. It has been universally recognized that adsorption of a species on a solid surface follows transport of the adsorbate from the bulk to the external surface of the adsorbent/passage through the liquid film attached to the solid surface/interactions with the surface atoms of the solid leading to chemisorptions or weak adsorption. In case of porous solids, after passing through the liquid film attached to the external surface, the adsorbate slowly diffuses into the pores and gets adsorbed. It is easily recognized that any of the above steps may be the slowest step determining the overall rate of the interactions and hence the kinetics of the adsorption process.

Sorption isotherm is a function to describe the transfer and retention of molecules at various concentrations from a mobile to a solid phase at constant temperature and gives very useful models to predict the mobility of molecules in the environment. Sorption isotherms can be used in order to determine the efficiency of an adsorbents ability to retain the adsorbate [20].

The objectives of this study are to characterize the prepared activated carbon from Pentapetes Phoenicea bio mass (Figure 1) as adsorbent and to investigate the kinetic adsorption of Lead (II) ion from an aqueous media onto the AC sorbent. In addition, actual groundwater polluted with heavy metal $\mathrm{Pb}$ (II) ion by the $\mathrm{AC}$ adsorbent was examined. Active carbons, like other types of carbon materials, are essentially composed of elemental carbon associated with other chemical elements chiefly hydrogen and oxygen. Physico-chemical analysis of adsorbent samples, FT-IR, XRD, Scanning electron microscopy (SEM), and EDX have been done in order to understand the structural changes during the activation process. Textural parameters such as BET surface area, volume and pore size distribution were evaluated by $\mathrm{N}_{2}$ adsorption. Although the nature and concentration of surface functional groups are characterized using several techniques including chemical titration methods (Boehm titration and pHpzc). X-ray photoelectron spectroscopy (XPS) is a surface-sensitive quantitative spectroscopic technique that measures the elemental composition at the surface of material [21]. The survey scans were collected from 0 to $1400 \mathrm{eV}$ and resulting scan given in Figure 5.

\section{EXPERIMENTAL}

\subsection{Chemicals}

All chemicals uses in the current study are AR quality purchased from Merck, Qualigens and Sd Fine chemical India. All solutions prepared and cleaning was done with double distilled water pH 7.01.

\subsection{Adsorbent carbon development \\ 2.2.1 Preparation of Activated carbon}

Pentapetes Phoenicea biomass based activated carbon prepared by physical activation followed by Chemical treatment (Figure 1). The chemically activated Pentapetes Phoenicea bio mass carbonwas prepared in this study by using the procedure suggested by $\mathrm{Hu}$ et al. [22] to produce carbon with larger proportion of mesopores, as follows. The dried Pentapetes Phoenicea bio mass collected from local agricultural fields of Vijayawada in bulk and cut in to small pieces (approximately $1.5 \mathrm{~mm}$ size) was impregnated with saturated $\mathrm{ZnCl}_{2}$ solution, using $\mathrm{ZnCl}_{2}$ to PPC weight ratio of $3: 1$. The impregnated sample was dried in an oven at $110^{\circ} \mathrm{C}$ for 24 hours. The dried sample was then carbonized in muffle furnace at $500^{\circ} \mathrm{C}$ for 2 hours. The resulting carbon was washed several times with hot double distilled water until the rinsing water was free from zinc and chloride ions $\left(\mathrm{AgNO}_{3} \mathrm{Test}\right)$. After several washings obtained carbon product was finally dried at $1100 \mathrm{C}$ overnight in hot air oven. The oxidizing agent used for the liquid-phase oxidation in order to incorporate oxygen functional groups onto physically and chemically activated carbon was $0.5 \mathrm{~N}$ nitric acid solution ( $M$ Kishore et al, 2014). The obtained carbon was designated as sample PPC. Last step is drying sample overnight before being stored in a desiccators for future uses. Yield of $\mathrm{AC}$ is calculated using following equation 1 :

$$
\text { Yiled }(\%)=\frac{\text { Weight of Carbon after activation }}{\text { Weight of the raw material }} \times 100 .(\mathrm{Eq} 1)
$$




\section{Available online at www.ijrat.org}

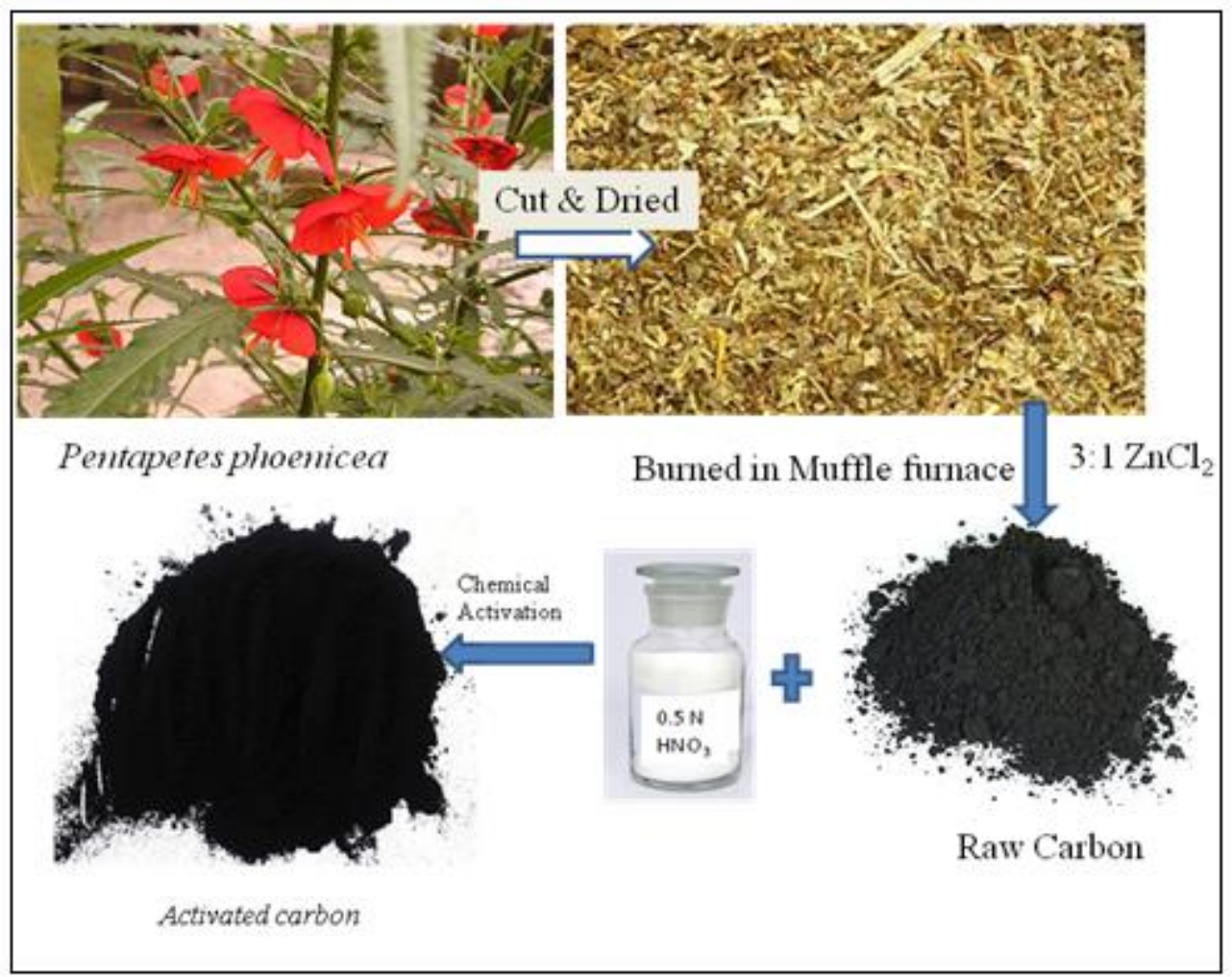

Figure 1: Schematic representation of Activated carbon preparation from Pentapetes Phoenicea Bio mass

\subsubsection{Preparation of lead (II) solution}

A stock solution of $\mathrm{Pb}^{2+}$ ion used in this study was prepared by dissolving an accurate quantity $\left(1598.9 \mathrm{mg}\right.$ ) of $\mathrm{Pb}\left(\mathrm{NO}_{3}\right)_{2}$ (purchased from Sigma Aldrich with purity $99.999 \%$ ) in deionized water. The concentration of the stock solution was $1000 \mathrm{mg} / \mathrm{L}$. Other concentrations were prepared by dilution of the stock solution. $\mathrm{Pb}(\mathrm{II})$ ion concentration in various samples was determined by Shimadzu model AA6650 atomic absorption spectrophotometer at the specified wavelength at $283.3 \mathrm{~nm}$. The calibration is carried out versus an aqueous standards curve.

\subsubsection{Adsorbent surface characterization}

The oxidized activated carbon sample PPC was characterized for the quantitative analysis of the acidic group contents on the carbon surface using Boehm titration, $\mathrm{pH}$ at the zero point charge (pHzpc) to assess the extent of surface acidity and $\mathrm{N}_{2}$ adsorption isotherms to determine the adsorbent porous properties, Evaluation of surface area for sample was done used BET method [23] (before and after adsorption of Lead (II) ion). Surface functional groups were estimated using FTIR spectroscopy. FTIR spectra recorded for PPC adsorbent on Thermo Scientific, Nicolet 6700 model to be between 400 and
$4000 \mathrm{~cm}^{-1}$. SEM (SEM JEOL model, JSM-5600) equipped with EDX Analyzer was used to identify the morphology of the PPC and conduct elemental analysis of the adsorbent. The XRD analysis on the prepared samples was made using a SCINTAG X'TRA AA85516 (Thermo ARL) X-ray diffractometer equipped with a Peltier cooled Si solid detector in order to determine the crystalline or amorphous nature. Monochromatized $\mathrm{Cu}-\mathrm{K} \alpha(0.150$ $54 \mathrm{~nm}$ ) was used as the radiation. The diffraction angle $(2 \theta)$ was varied from $0^{\circ}$ to $80^{\circ} \mathrm{C}$. The $\mathrm{X}$-ray diffraction patterns were collected with a scan rate of $4.2^{\circ} \mathrm{C} / \mathrm{min}$. X-ray photo electron spectral (XPS) analysis was carried out before and after the adsorption process had run for $3 \mathrm{~h}$ using an Escalab $250 \mathrm{Xi}$ spectrophotometer (Themo Scientific, USA) with $\mathrm{MgK} \alpha$ radiation at $1253.6 \mathrm{eV}$. The method of Boehm (1994) [24] was used to determine titratable functional groups for negative surface charge on the carbons.

\subsubsection{Adsorption Studies}

Adsorption mechanisms depend on the characteristics of the adsorbate and adsorbent, adsorbate-adsorbent interactions and the system conditions like $\mathrm{pH}$, temperature, etc. The interactions may also involve the solvent molecules and the 


\section{Available online at www.ijrat.org}

attractive forces may be of different nature. Active carbon has been employed for the removal of aqueous contaminants from liquid media for many years. Adsorption data can be found in the literature and methods exist for the design of adsorbents, sometimes without doing any preliminary tests. It is not, however, possible to predict the effectiveness of carbon in treating a given liquid on a purely theoretical basis. In most cases, therefore, tests have to be carried out and each application has to be considered individually. If a sorbent is being considered for a new application, a laboratory investigation is essential to determine the process parameters

Batch equilibrium experiments were carried out using PPC as sorbent. A series of flasks containing standard lead nitrate solutions of varying concentrations prepared from lead nitrate and a fixed mass of PPC $(1 \mathrm{~g} / \mathrm{L})$ were agitated in a rotary shaker at $2000 \mathrm{rpm}$ at room temperature $\left(30 \pm 1^{\circ} \mathrm{C}\right)$ for 30 minutes. Lead ions uptake experiments were conducted under constant $\mathrm{pH}$ value between 2 and 9 . After equilibration, the lead nitrate solutions were filtered through what man 42 papers and analyzed. Lead-free and sorbent-free blanks were used as controls. The percentage removal of Lead (II) ionand the amount adsorbed (in $\mathrm{mg} / \mathrm{g}$ ) have been calculated by using the following relationships:

\section{Percentage removal $=100(\mathrm{Ci}-\mathrm{Ce}) / \mathrm{Ci}$ Amount adsorbed $\left(\mathrm{Q}_{\mathrm{e}}\right)=(\mathrm{Ci}-\mathrm{Ce}) / \mathrm{m}$}

Where $\mathrm{Ci}$ is the initial concentration and $\mathrm{Ce}$ is the final concentration of the Lead (II) ion respectively, and ' $\mathrm{m}$ ' is the weight of adsorbent in $\mathrm{g} / \mathrm{L}$. Adsorption experiments have been carried out to determine the effect of initial $\mathrm{pH}$, contact time, initial concentration of Lead (II) ion. The data have been analyzed in the light of adsorption isotherms, adsorption kinetic equations and intra particle diffusion model.

\section{RESULTS AND DISCUSSION}

\subsection{Physico-chemical characterization}

In mass production of activated carbon, relatively high product yield is expected to ensure the economic viability. The yield obtained in this study was $22.4 \%$. The finding by far is comparable to the published results by Yang et al. [25] whom also investigated the performance of single step activation on coconut shell. Based on their findings, the yield was in range of 4 to $20 \%$ only, irrespective of the temperature, holding time and gas flow rate. The amounts and distribution of oxygen acidic groups and basic groups on activated carbon surface, as determined from Boehm titration, are shown in table 1. The $\mathrm{HNO}_{3}$ oxidation of PPC gave the acidic functional group content order is carboxylic acid>phenolic>lactonic. This maximum creation of carboxylic acid content by treatment with $\mathrm{HNO}_{3}$ was also reported in the previous work [26]. Table 1 also listed the value of point of zero charge $\left(\mathrm{pH}_{\mathrm{ZPC}}\right)$ exhibit lower $\mathrm{pH}_{\mathrm{ZPC}}$ value. This indicates that the original carbon which have a basic surface become acidic after chemical treatment. The order of the $\mathrm{pH}_{\mathrm{ZPC}}$ value is in agreement with the amount of acidic functional groups obtained from Boehm titration, that is, the higher the content of acidic functional groups, the lower is the $\mathrm{pH}_{\mathrm{ZPC}}$ [27]. $\mathrm{pH}_{\mathrm{ZPC}}$ of PPC sample was found at 5.92 (Table 1), When the solution $\mathrm{pH}$ was below the ZPC of PPC ( $\mathrm{pH}<5.92)$, the PPC surface was negatively charged, and when the $\mathrm{pH}$ of the solution was above the $\mathrm{pH}$ ZPC of PPC ( $\mathrm{pH}>5.92)$, the PPC surface was negatively charged. The BET surface area found to be $324.651 \mathrm{~m}^{2} / \mathrm{g}$. It is more than some other active carbons reported in literature. This feature is more important in assessing the effectiveness of adsorption process. Further, the reduction in surface area from 324.651 to $307.614 \mathrm{~m}^{2} / \mathrm{g}$, Total pore volume from $0.276 \mathrm{~cm}^{3} / \mathrm{g}$ to 0.203 indicated the loading of $\mathrm{Pb}$ (II) ion onto the surface of PPC adsorbent sample.

Table 1: Characteristics of activated carbon

\begin{tabular}{|c|c|c|c|c|c|c|c|c|c|}
\hline \multirow{2}{*}{$\begin{array}{l}\text { Carbon } \\
\text { sample }\end{array}$} & \multirow{2}{*}{$\frac{\mathrm{S}_{\mathrm{BET}}}{\left(\mathrm{m}^{2} / \mathrm{g}\right)}$} & \multicolumn{2}{|c|}{$\mathrm{V}_{\text {mic }}$} & \multicolumn{2}{|c|}{$\mathrm{V}_{\text {meso }}$} & \multirow{2}{*}{$\frac{\mathrm{V}_{\mathrm{T}}}{\left(\mathrm{cm}^{3} / \mathrm{g}\right)}$} & \multirow{2}{*}{$\frac{\mathrm{D}}{\mathrm{nm}}$} & \multirow[t]{2}{*}{$\mathrm{pH}_{\mathrm{PZC}}$} & \multirow[t]{2}{*}{ yield } \\
\hline & & \multicolumn{2}{|c|}{$\left(\mathrm{cm}^{3} / \mathrm{g}\right) \quad(\%)$} & $\left(\mathrm{cm}^{3} / \mathrm{g}\right)$ & $(\%)$ & & & & \\
\hline PPC & 324.651 & 0.21 & 76.09 & 0.066 & 23.91 & 0.276 & 1.102 & 5.92 & $22.4 \%$ \\
\hline \multicolumn{10}{|c|}{ Boehm titration } \\
\hline \multicolumn{2}{|c|}{ carboxylic acid } & \multicolumn{2}{|c|}{$0.324 \mathrm{~m} . \mathrm{mol} / \mathrm{g}$} & enolic & \multicolumn{2}{|c|}{$0.061 \mathrm{~m} . \mathrm{mol} / \mathrm{g}$} & ctonic & \multicolumn{2}{|c|}{$0.007 \mathrm{~m} . \mathrm{mol} / \mathrm{g}$} \\
\hline
\end{tabular}

Note: $S_{B E T}=B E T$ surface area $; V_{\text {mic }}=$ micropore volume $; V_{\text {meso }}=$ mesopore volume $; V_{T}=$ total pore volume; $D$ = average pore diameter.

Fourier transform infrared (FT-IR) published by other authors, among the papers spectroscopy was applied to the determination of considering the FTIR spectra of the activated carbons, functional groups on the surfaces of AC sample. In these with the bands covering similar or the same Figure 2 the assignment of the bands observed for ranges of the wavelengths as observed for the before adsorption of Lead (II) ion, basing on the data investigated carbons were chosen. Several 


\section{Available online at www.ijrat.org}

characteristics bands were observed in the FT-IR spectrum of activated carbon of PPC and each of the bands were assigned to specific functional group based on the previous assignments made in literature. Even though a cluster of functional groups were present on the carbon surface, the prominent among them were a sharp and intense band centered around $1655 \mathrm{~cm}^{-1}$ which was attributed to the carbonyl $(\mathrm{C}=\mathrm{O})$ stretching vibration of quinine [28]. Carbonyl functional groups were known to be pronounced in oxidized carbon materials rather than the original parent carbon material. In addition, a broad and intense band was observed in the range of 3100-3300 $\mathrm{cm}^{-1}$, centered at $3162 \mathrm{~cm}^{-1}$ and it was attributable to the $\mathrm{O}-\mathrm{H}$ stretching vibration of surface hydroxyl groups as well as to the adsorbed water. 1460 and $1382 \mathrm{~cm}^{-1}$ due to the in plane bending vibration of $\mathrm{C}$ $\mathrm{H}$ of methylene group [29]; 1000-1300 $\mathrm{cm}^{-1}$ range peaks due to $\mathrm{C}-\mathrm{O}$ stretching in phenols, alcohols, acids, ethers and esters [30]. The absence of specific peak pertains to $\mathrm{C}-\mathrm{Pb}$, suggested that the adsorption process was physisorption but not chemisorptions [31]. Further it was confirmed by the peak values significantly not changed after adsorption process.

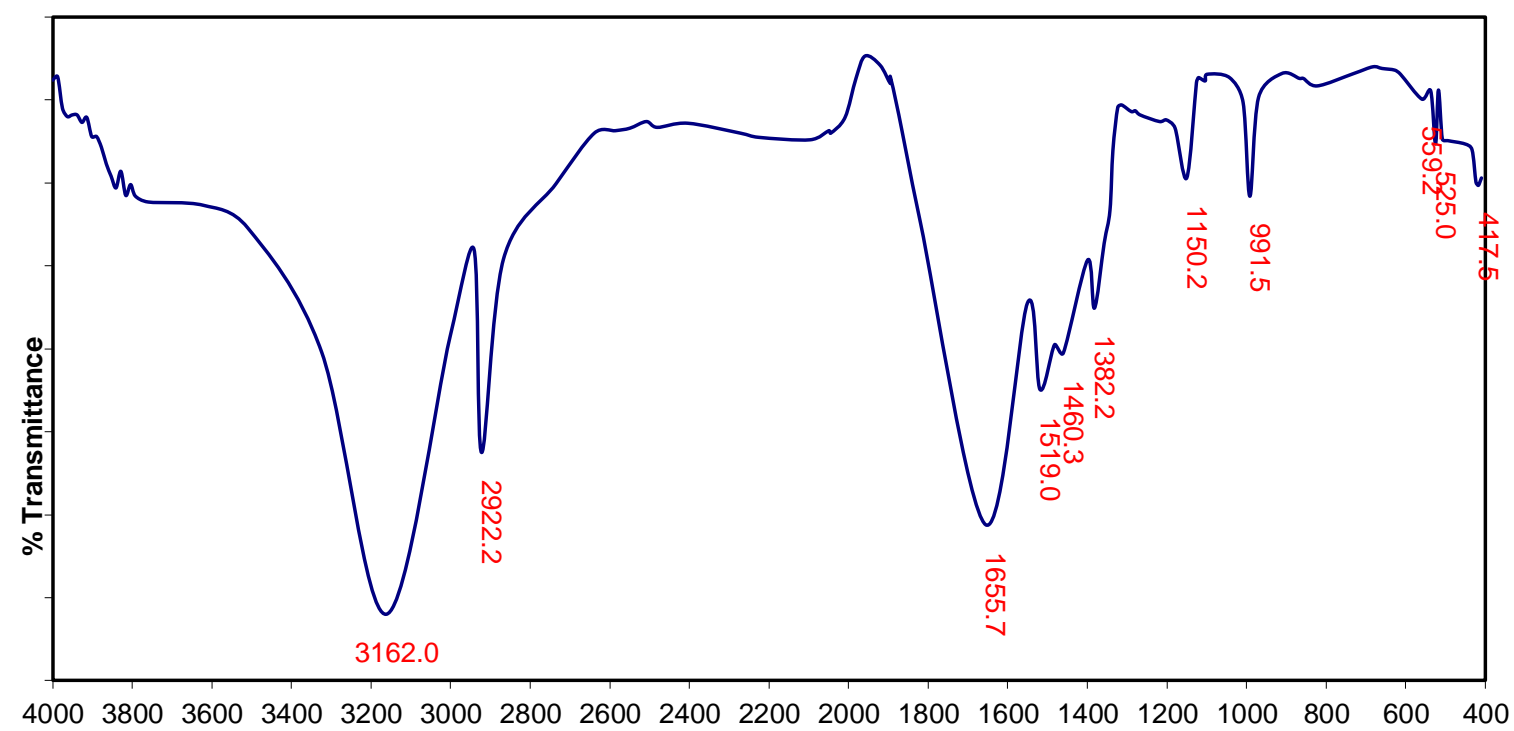

wavelength $\left(\mathrm{cm}^{-1}\right)$

Figure 2: FT IR spectra of Activated carbon sample

Surface morphology is the study of the form or shape of a material. Scanning lectron Microscope (SEM) provides valuable information regarding external and internal features of the particles of materials studied. According to the SEM analysis (Figure 3), it can be seen clearly that the structure of the activated carbon was smoothed and porous with many cavities. This was due to the devolatilization of carbonaceous matters that allows the release of reaction gases from the core of particles to outer surroundings [32].

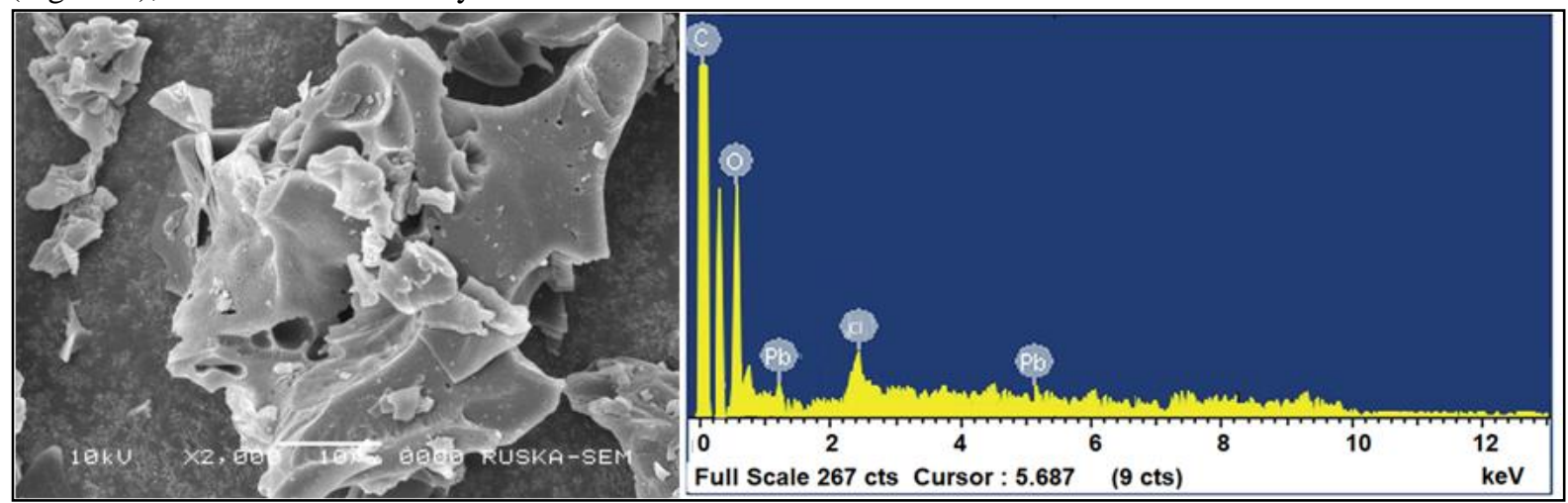

Figure 3: SEM(left)- EDX(Right) spectra of activated carbon sample after adsorption with $\mathrm{Pb}(\mathrm{II})$ ion 


\section{Available online at www.ijrat.org}

The EDX studies provided the quantitative analysis on the elemental composition by weight percent and atomic percent. On average, lignocellulosic materials compose of 30-60 wt $\%$ carbon, 30-40wt\% oxygen, 5-6 $\mathrm{wt} \%$ hydrogen and approximately $1 \mathrm{wt} \%$ of inorganic contents [33]. In the current study $\mathrm{Pb}$ (II) ions appeared on the surface of AC after adsorption process (Figure 3). Indicate the successful adsorption process with PPC.
The crystalline nature of prepared Carbon adsorbent sample PPC was determined using XRD, and the observed pattern was given in Figure 4. The XRD pattern of unloaded (before adsorption) PPC shows poor crystallinity with one sharp peak at $2 \theta^{\circ}=27.65$. This peak was attributed to $\mathrm{CaCO}_{3}$ precipitation. This observation is consistent with FTIR scans and previously reported results (Cao and Harris, 2010) [34] in which the crystalline phase of $\mathrm{CaCO}_{3}$ was identified using XRD at $2 \theta^{\circ}=29$ and 29.32, respectively.

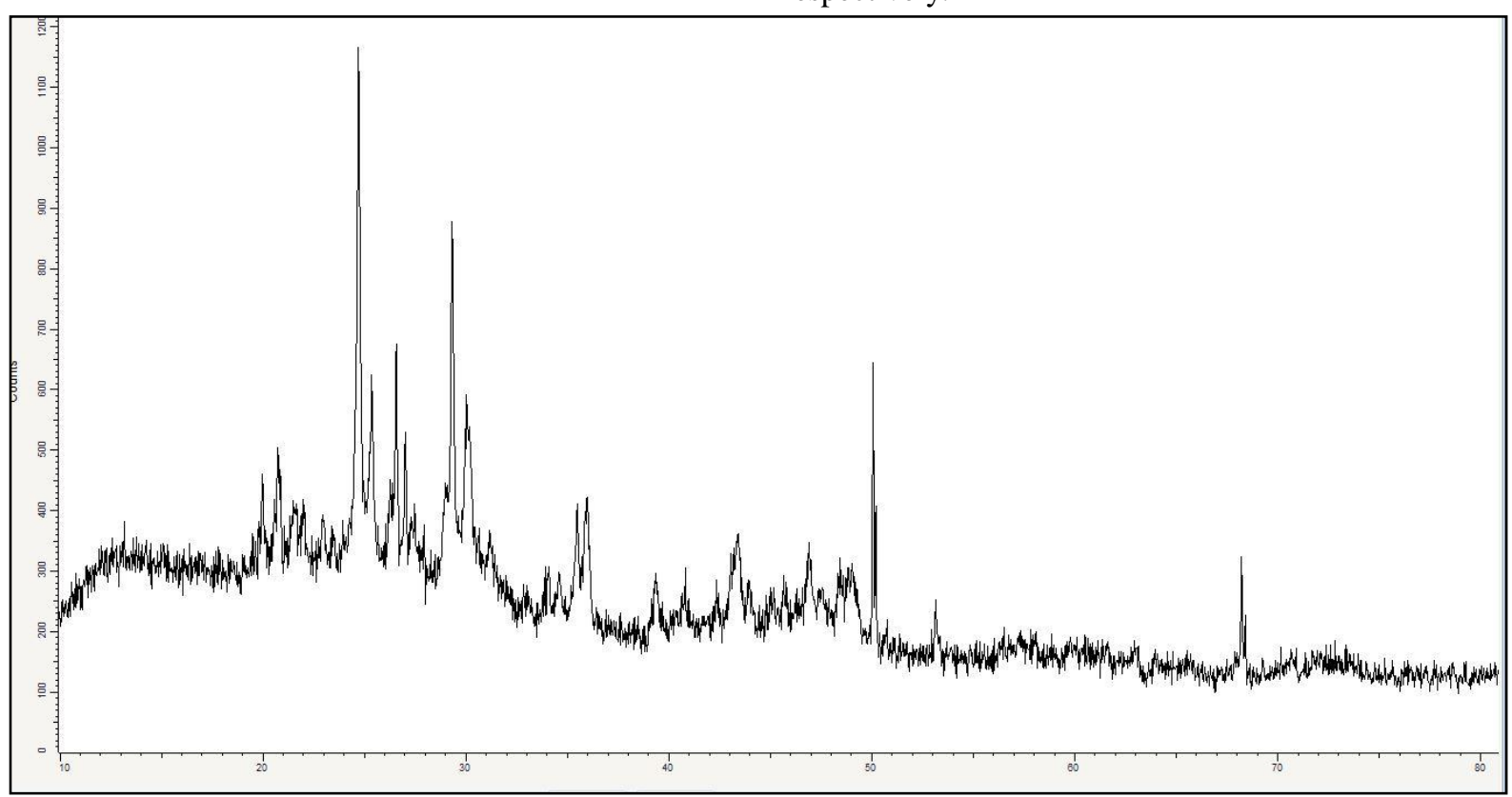

Figure 4: XRD spectra of activated carbon sample

$\mathrm{X}$-ray photoelectron $(\mathrm{XP})$ spectra provide the relative frequencies of binding energies of electrons detected, measured in electron-volts (eV). The high-resolution scans of XPS analysis (Figure 5) were performed over the 280-294, 527-540 and 680-700 eV ranges (C1s, $\mathrm{O} 1 \mathrm{~s}$ and F1s spectra) for present samples before and after Lead (II) ionadsorption. XPS spectra of the C1s and $\mathrm{O} 1 \mathrm{~s}$ regions showed that the carbon-based surface oxide groups were present in the sample. Deconvolution of the $\mathrm{C} 1 \mathrm{~s}$ spectra was yielded three peaks with different binding energies representing graphitic carbon $(283.24 \mathrm{eV})$, carbon present in structural hydroxy- and ether-like groups $(284.20 \mathrm{eV})$, carboxyl or ester (anhydride) groups (286.12eV). These assignments agreed well with the extensive XPS studies made on the commercially available carbons used as catalyst supports (C. Moreno-Castilla et al 2000). The O1s spectra for the carbon samples displayed two main peaks corresponding to the $\mathrm{C}=\mathrm{O}$ $(529.78 \mathrm{eV})$ and $\mathrm{C}-\mathrm{O}(531.37 \mathrm{eV})$ moieties [35]. After the adsorption of Lead (II) ion with activated carbon sample (PPC), the high-resolution narrow scan for $\mathrm{Pb}$ $4 \mathrm{f}$ was observed. The main peak at nearly $140.24 \mathrm{eV}$ indicated the adsorption of $\mathrm{Pb}(\mathrm{II})$ ion on activated carbon. In the present investigation the peak in XPS spectra for $\mathrm{Pb}(\mathrm{II})$ ion was not observed before adsorption of $\mathrm{Pb}(\mathrm{II})$ ion with activated carbon sample (Figure 5). It was concluded from the obtained results that the sample was richer in carbon and oxygen than any other elements. Some $\mathrm{Pb}(\mathrm{II})$ ions were found to be trapped at the surface of the activated carbon after adsorption process. 


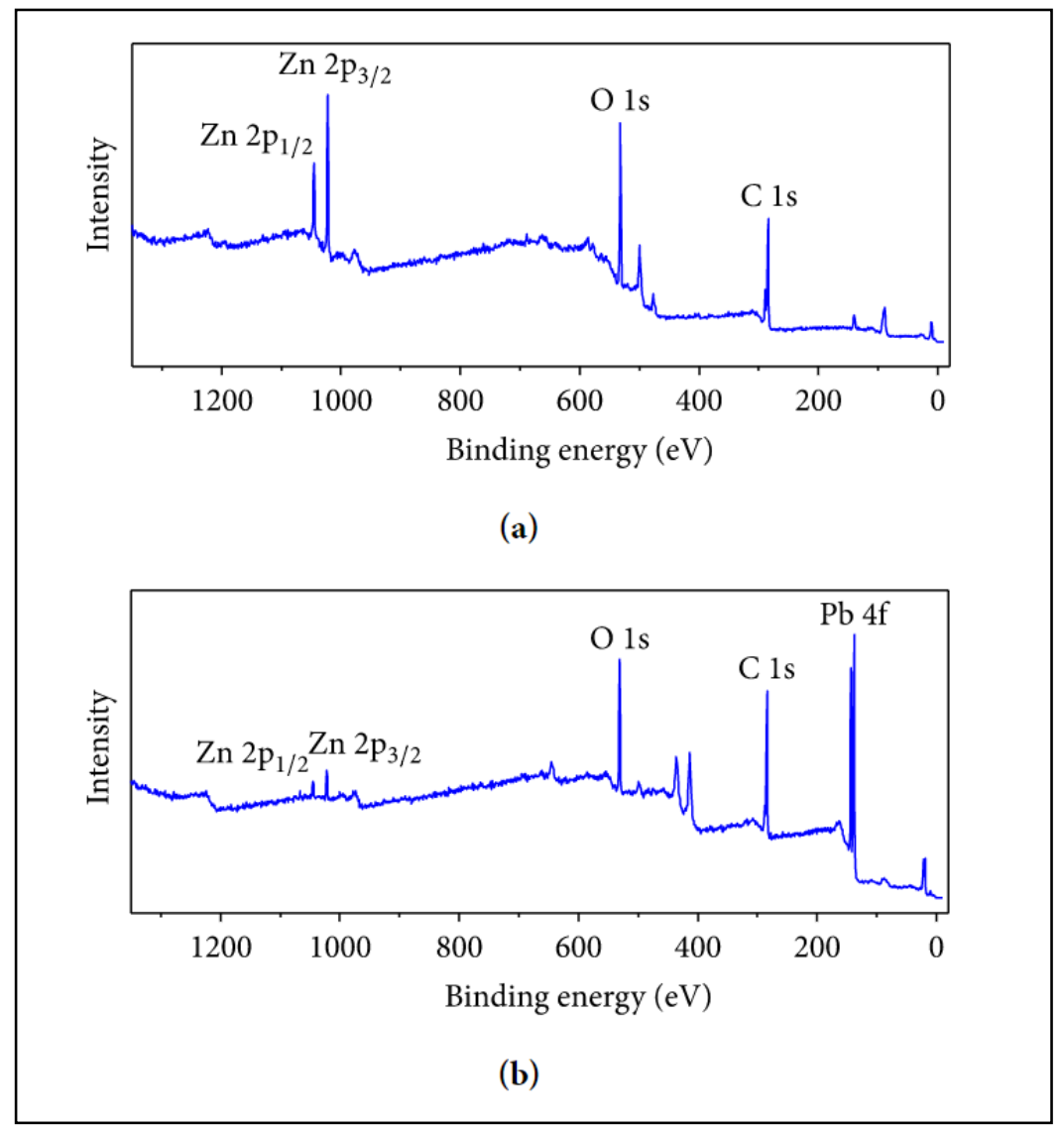

Figure 5: XPS Survey Scan spectra of PPC before (above) and after adsorption (below) process

\section{2}

\section{Effect of adsorbate $\mathrm{pH}$}

Research concerning the removal of lead and other heavy metal cations by oxidized carbons has been summarized by Tarkovskaya et al [36] and Strazhesko [37]. The authors showed that significant differences in sorption of various metal ions by oxidized carbons are observed over a wide range of $\mathrm{pH}$ values. To check the effect of $\mathrm{pH}$ on $\mathrm{Pb}(\mathrm{II})$ adsorption using activated carbon prepared from dates stones as adsorbent, experiments were conducted by varying $\mathrm{pH}$ from 2.0 to 10.0 with an initial concentration of $100 \mathrm{mg} / \mathrm{L}$. The results obtained for adsorbent are shown in Figure 6.

The amount of adsorbed $\mathrm{Pb}(\mathrm{II})$ increase from $18.66 \mathrm{mg} / \mathrm{g}$ to $19.47 \mathrm{mg} / \mathrm{g}$. The fact that the amount of $\mathrm{Pb}$ (II) removal at low $\mathrm{pH}$ is considerably lower may be accounted for by the competition between $\mathrm{Pb}^{2+}$ and $\mathrm{H}+$ ions the active sites on sorbent surface. The decreasing of the amount of adsorbed $\mathrm{Pb}$ (II) above $\mathrm{pH}$ $=5$ due to formation of soluble hydroxyl complexes. It is assumed that $\mathrm{OH}$ - in the alkaline medium effects firstly hydrolysis products of $\mathrm{Pb}(\mathrm{OH})^{+}$, then affect $\mathrm{Pb}(\mathrm{OH})_{2}$ hydrolysis complexes, also, these effects decrease the adsorption. We can note that the optimal $\mathrm{pH}=5$. At low $\mathrm{pH}$, the surface of the adsorbent was surrounded by hydronium ions that compete with metal ions, which prevented the metal ions from approaching the binding sites on the adsorbent. The increase in metal removal as $\mathrm{pH}$ increases can be explained on the basis of a decrease in competition between hydronium ions and metal species for the surface sites. At $\mathrm{pH}=5.0$, the adsorption capacity of PPC almost reaches the maximum value. Because the speciation diagram of lead shows that at $\mathrm{pH}>5.0$ the species such as $[\mathrm{Pb}(\mathrm{OH})]^{+}, \quad\left[\mathrm{Pb}_{3}(\mathrm{OH}) 4\right]^{+}$, and $\left[\mathrm{Pb}(\mathrm{OH})_{2}\right]$ will be produce[38]. In order to guarantee to truly examine the adsorption property of carbon sample as well as to avoid precipitation of $\mathrm{Pb}(\mathrm{II})$ ions, all the following experiments were conducted at $\mathrm{pH}=5.0$. In this study, PPC was used to adsorb $\mathrm{Pb}(\mathrm{II})$ ions, which are positively charged. The adsorption process could thus only occur when the solution $\mathrm{pH}$ was lower than the $\mathrm{pH}$ at the PZC because the PPC surface had a positive charge. 


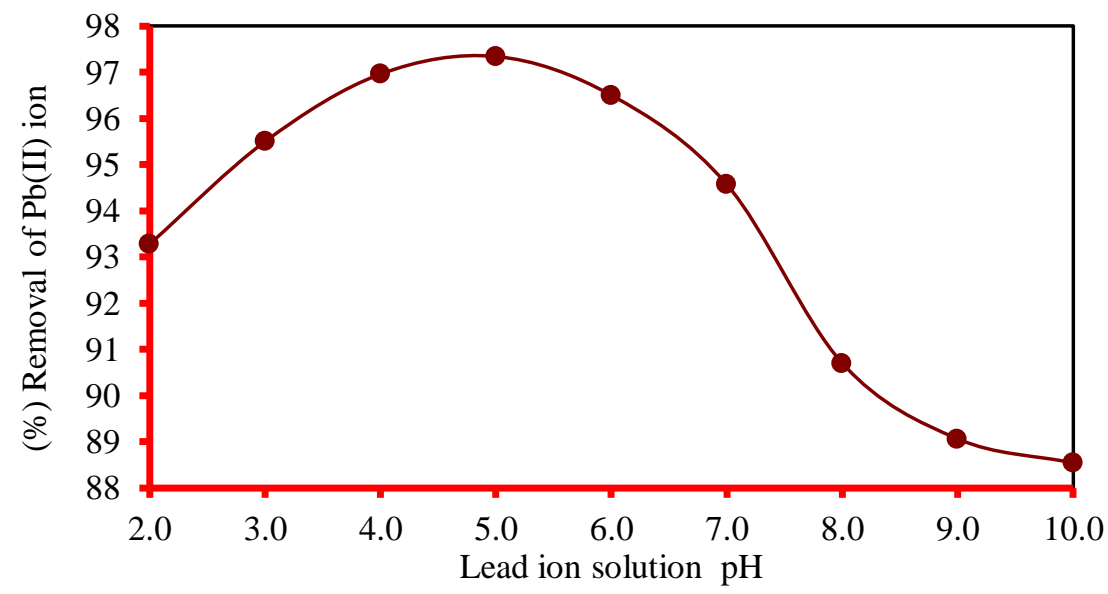

Figure 6: Effect of Lead (II) ion solution $\mathrm{pH}$ on the Adsorption process at optimum conditions ( $\mathrm{Ci}=100 \mathrm{mg} / \mathrm{L}$, particle Size 75 microns, Dose of the Adsorbent $5 \mathrm{~g} / \mathrm{L}$ agitation time 35 minutes)

\subsection{Effect of concentration}

The effect of initial $\mathrm{Pb}^{2+}$ ion concentrations on the adsorption efficiency of the studied agricultural wastes is shown in Figure 7. Adsorption experiments were carried out at different initial $\mathrm{Pb}^{2+}$ concentrations ranging from $5 \mathrm{mg} / \mathrm{L}$ to $200 \mathrm{mg} / \mathrm{L}$. It was observed as a general trend that there is a decrease of the removal percentage with increase in initial concentration from
5 to $110 \mathrm{mg} / \mathrm{L}$. These results may be explained on the basis that the increase in the number of ions competing for the available binding sites and also because of the lack of active sites on the adsorbent at higher concentrations. Therefore, more metal ions were left un-adsorbed in solution at higher concentration levels [39].

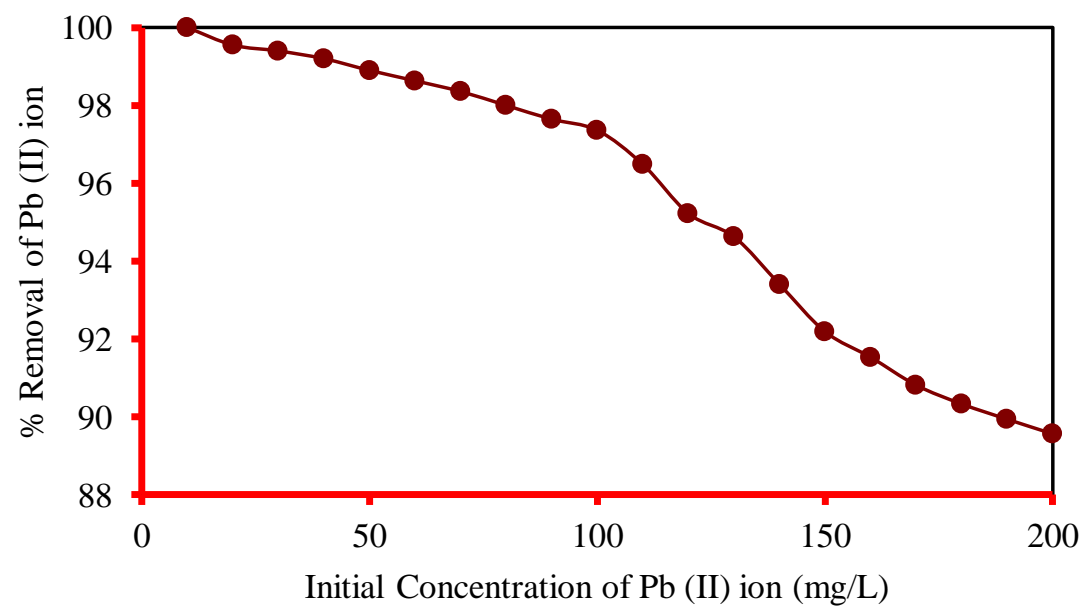

Figure 7: Effect of Lead (II) ion solution concentration on the Adsorption process at optimum conditions ( $\mathrm{pH}=7.02$, particle Size 75 microns, Dose of the Adsorbent $5 \mathrm{~g} / \mathrm{L}$, agitation time 35 minutes)

3.4

\section{Effect of time}

Equilibrium time is one of the most important parameters in the evaluation of adsorption efficiency. Rapid uptake and quick establishment of equilibrium time imply the efficiency of a particular adsorbent PPC in wastewater treatment. The kinetics of lead (II) ion adsorption onto activated carbon in Figure 8 show the extent of adsorption is rapid during the initial stages, becoming slow during the later stages until saturation is achieved. It was found that $98.1 \%$ of $\mathrm{Pb}^{2+}$ removal occurred in the first $30 \mathrm{~min}$ at initial time or the equilibrium can be assumed to be achieved after 30 minutes. Equilibrium being basically due to the saturation of the active site and slow pore diffusion, at which time further adsorption cannot take place [40]. Rapid uptake and quick establishment of equilibrium time imply the efficiency of prepared activated carbon 
as a good adsorbent in terms of usage in water treatment.

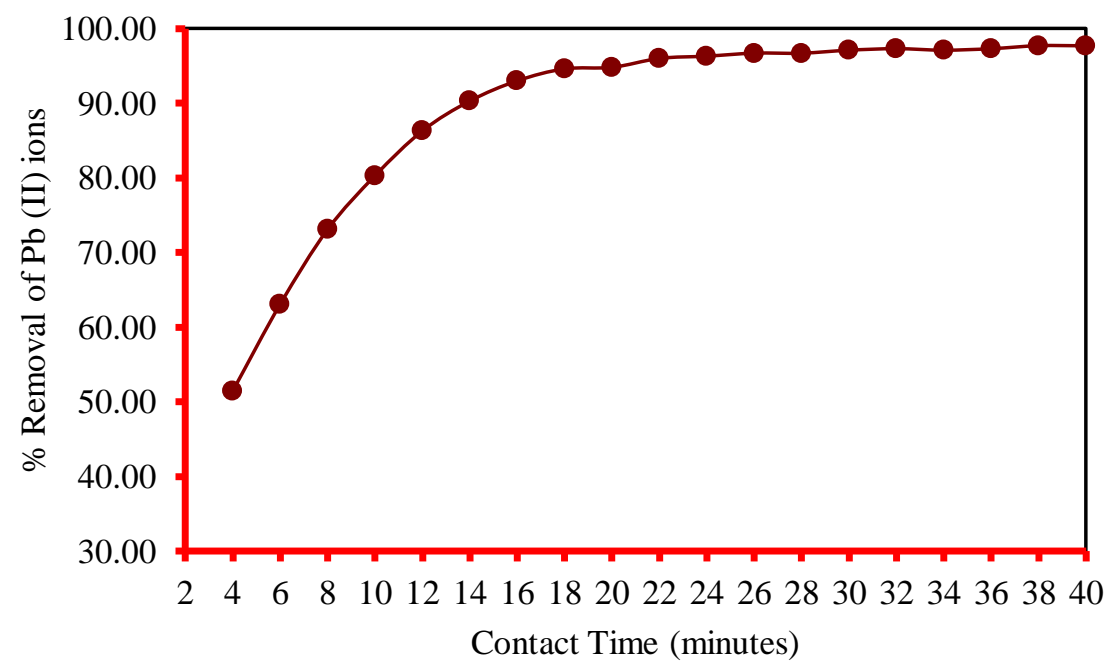

Figure 8: Effect of Agitation time on the Adsorption process at optimum conditions $(\mathrm{pH}=7.02, \mathrm{Ci}=100 \mathrm{mg} / \mathrm{L}$, particle Size 75 microns, Dose of the Adsorbent $5 \mathrm{~g} / \mathrm{L}$ )

\subsection{Isotherm Study}

Adsorption isotherms are mathematical models that describe the distribution of the adsorbate species between liquid and adsorbent, based on a set of assumptions that are mainly related to the heterogeneity/homogeneity of the adsorbent, the type of coverage and possibility of interaction between the adsorbate species. In this work, two widely used isotherms have been applied; The Langmuir and Freundlich isotherms. When using linear adsorption isotherm models and rate expressions in this work, the coefficient of correlation $\left(\mathrm{R}^{2}\right)$ is used to determine how well the data fits the model. $\mathrm{R}^{2}$, is unit less between $0-1$ and can be defined as the ratio of the variation in the data that can be predicted by the model and the total variation [41]. Higher $\mathrm{R}^{2}$ indicates a better fit for data to the model [42].

\subsubsection{Freundlich Isotherm}

Freundlich isotherm is widely applied in heterogeneous systems especially for Inorganic/organic pollutants or highly interactive species on activated carbon. The slope ranges between 0 and 1 is a measure of adsorption intensity or surface heterogeneity, becoming more heterogeneous as its value gets closer to zero. The Freundlich adsorption isotherm represents the relationship between the amount of metal adsorbed per unitmass of the adsorbent $q \mathrm{e}$ and the concentration of the metal in solution at equilibrium.

The Freundlich adsorption isotherm [43] is:

$$
q e=K_{f} C_{e}^{1 / n}
$$

The Freundlich adsorption isotherm can be linearized by taking logarithms to find the parameters $K_{f}$ and n:

$$
\log q e=\log K_{f}+\left(\frac{1}{n}\right) \log C e
$$

The logarithmic plot of the Freundlich expression for the amount of $\mathrm{Pb}$ (II) ion adsorbed per unit mass of the adsorbent (qe) and the concentration of $\mathrm{Pb}(\mathrm{II})$ at equilibrium (Ce) is shown in Figure 9. Examination of the data shows that the Freundlich isotherm provides a good description of the data over the concentration range ( 5 to $100 \mathrm{mg} / \mathrm{L}$ ). The values of $K_{f}$ and $n$ were calculated from the slope and intercept of the plot. Table 2 shows the Freundlich constant and linear correlation coefficient. 
Available online at www.ijrat.org

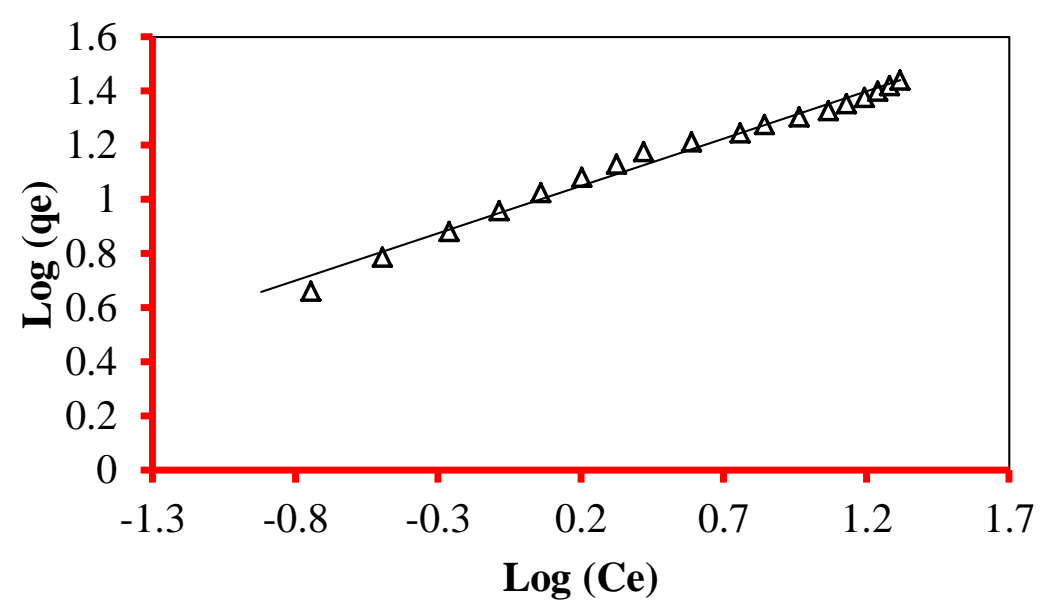

Figure 9: Prediction of Freundlich isotherm curve for the adsorption of $\mathrm{Pb}^{2+}$ ion onto PPC adsorbent

\subsubsection{Langmuir isotherm}

The Langmuir isotherm model is based on the theoretical assumptions that available sorption sites are identical, energetically homogeneous and can only retain one molecule of the substance [44]

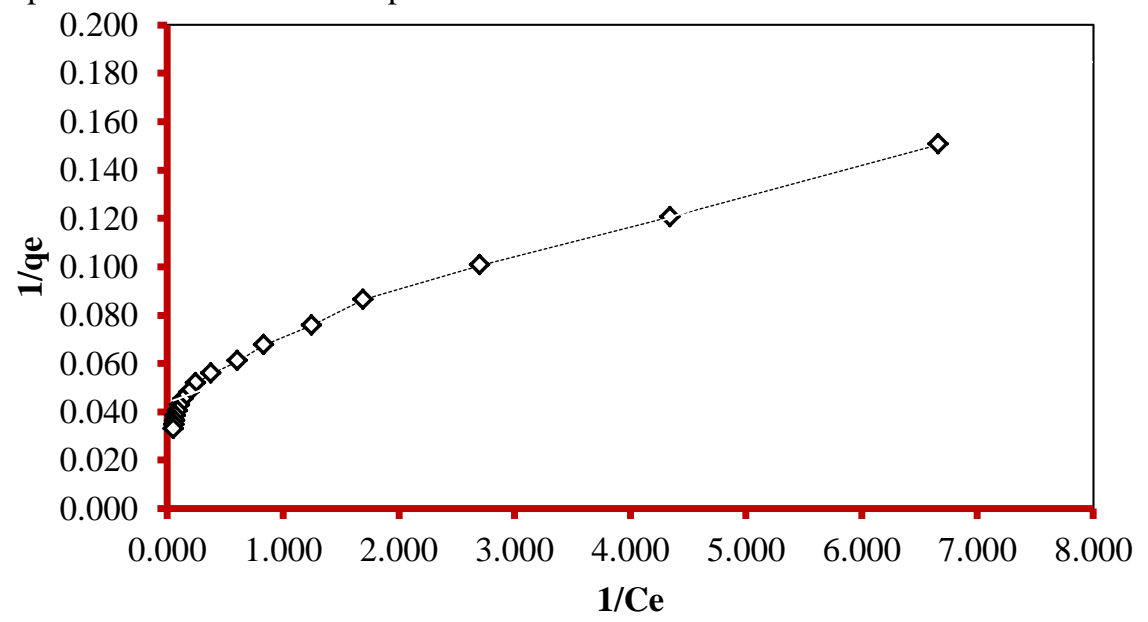

Figure 10: Prediction of Langmuir isotherm curve for the adsorption of $\mathrm{Pb}^{2+}$ ion onto $\mathrm{PPC}$ adsorbent

The Langmuir equation is commonly written as [45];

$q e=a b C e /(1+b C e)$,

where $q e$ is the amount adsorbed (mg/g) and $C e$ is the equilibrium concentration of adsorbate $(\mathrm{mg} / \mathrm{L}), a$ and $b$ are the Langmuir constants related to capacity and energy of adsorption, respectively. The linear form of the Langmuir isotherm can be expressed as,

$1 / q e=(1 / a)+(1 / b a C e)$

When $1 / q e$ is plotted against $1 / C e$, a straight line with slope $1 / b a$ is obtained which shows that the adsorption follows the Langmuir isotherm as shown in Figure 10.
The Langmuir constants ' $b$ ' and ' $a$ ' are calculated from the slope and intercept with $\mathrm{Y}$-axis.

The isotherm parameters along with the correlation coefficients (r-values) for adsorbents are presented in Table 2. The observed linear relationships as evidenced by r-values close to unity (0.9). The applicability of Langmuir isotherm model indicates the formation of monolayer coverage of adsorbate on outer surface of the adsorbent. Further, the essential characteristics of a Langmuir isotherm can be expressed in terms of dimensionless separation factor, and describe the type of isotherm defined by;

$\mathrm{R}_{\mathrm{L}}=1 /(1+\mathrm{b} C \mathrm{i})$ 


\section{Available online at www.ijrat.org}

Where, $\mathrm{Ci}$ is the initial concentration of Lead (II) ion(in $\mathrm{mg} / \mathrm{L}$ ) and ' $\mathrm{b}$ ' is the Langmuir constant (in $\mathrm{g} / \mathrm{L}$ ). The separation factor RL indicates the isotherm's shape and the nature of the adsorption process as unfavourable $\left(\mathrm{R}_{\mathrm{L}}>1\right)$, linear $\left(\mathrm{R}_{\mathrm{L}}=1\right)$, favourable $(0<$ $\left.\mathrm{R}_{\mathrm{L}}<1\right)$ and irrereversible $\left(\mathrm{R}_{\mathrm{L}}=0\right)$. In the present study the values of $\mathrm{R}_{\mathrm{L}}$ (Table 2 ) being 0.3703 and 0.0247 respectively for the adsorbent PPC indicating that the sorption process is favorable with the selected adsorbent sample. Where $b$ and $\mathrm{Ci}$ are terms appearing in Langmuir isotherm. From the values obtained from table 2, it was found that Freundlich isotherm is best fit when compared with Langmuir isotherm.

\subsection{Kinetic study}

Adsorption rate was studied by the finite batch method. Determination of the adsorption rate is an important factor to understand the processes in the system. It is also important to understand the adsorption rates in order to properly design solutions for pollutant removal by sorption[46]. The extent of lead sorption is monitored by measuring the change of agitation time at optimum concentrations. As aforementioned, a lumped analysis of adsorption rate is sufficient to practical operation from a system design point of view. The commonly employed lumped kinetic models, namely, (a) the intraparticle diffusion model, (b) the Pseudo First order equation, and (c) the pseudo-second-order equation are presented below.

Table 2: Adsorption isotherms and Kinetic parameters for the removal of $\mathrm{Pb}^{2+}$ ion using $\mathrm{PPC}$ as adsorbent carbon

\begin{tabular}{|c|c|c|}
\hline $\begin{array}{l}\text { Isotherm } \\
\text { Parameter }\end{array}$ & & Values \\
\hline \multirow{3}{*}{$\begin{array}{l}\text { Freundlich } \\
\text { isotherm }\end{array}$} & $K_{f}$ & 0.979 \\
\hline & $1 / n$ & 0.349 \\
\hline & $\mathrm{R}^{2}$ & 0.986 \\
\hline \multirow{4}{*}{$\begin{array}{l}\text { Langmuir } \\
\text { isotherm }\end{array}$} & $\mathrm{R}^{2}$ & 0.942 \\
\hline & 'a' (mg/g) & 0.043 \\
\hline & 'b' (g/L) & 0.017 \\
\hline & $\mathrm{R}_{\mathrm{L}}$ & 0.3703 \\
\hline \multicolumn{3}{|c|}{ Kinetics of Lead Adsorption } \\
\hline \multirow{3}{*}{$\begin{array}{l}\text { Lagergren's } \\
\text { equation }\end{array}$} & $K_{1}$ & 0.162 \\
\hline & $\mathrm{R}^{2}$ & 0.981 \\
\hline & $\mathrm{q}_{\mathrm{e}}$ & 2.477 \\
\hline \multirow{2}{*}{$\begin{array}{l}\text { Pseudo- } \\
\text { second order } \\
\text { rate equation }\end{array}$} & $\mathrm{K}_{2}$ & 0.056 \\
\hline & $\mathrm{R}^{2}$ & 0.997 \\
\hline
\end{tabular}

\begin{tabular}{|l|l|l|}
\hline & $\mathrm{q}_{\mathrm{e}}$ & 0.147 \\
\hline $\begin{array}{l}\text { Intra particle } \\
\text { Diffusion } \\
\text { model }\end{array}$ & $\mathrm{K}_{\mathrm{ad}}$ & 1.662 \\
\hline & $\mathrm{R}^{2}$ & 0.781 \\
\hline & $\mathrm{C}$ & 6.074 \\
\hline
\end{tabular}

\subsubsection{Pseudo First order Kinetics}

Firstly, the adsorption rate of the sorbents was analyzed using Lagergren's pseudo first-order rate equation in linear form as follows [47]:

$$
\log (q e-q t)=\log (q e)-\frac{k_{1}}{2.303 t}
$$

where qe and qt are adsorption capacity at equilibrium and at time $\mathrm{t}$, respectively; and $\mathrm{k} 1$ is the rate constant of pseudo first-order adsorption $\left(\mathrm{min}^{-1}\right)$. Values of $k_{l}$ and $q e$ can be determined from the slope and intercept of the plot of $\ln (\mathrm{qe}-\mathrm{qt})$ versus $\mathrm{t}$, respectively. The data in Table 2 show the pseudo first-order adsorption rates were not suitable to describe the experimental data, considering the range of values for $\mathrm{R}^{2}(0.981)$.

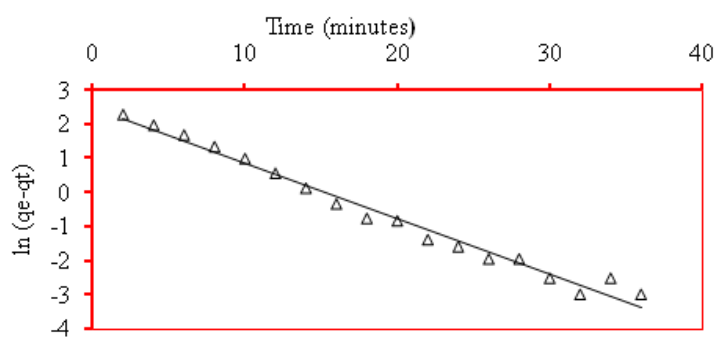

Figure 11: Pseudo First order plot for Lead (II) ion adsorption onto PPC.

\subsubsection{Pseudo second order}

The linear form of pseudo-second-order kinetic mode [48] is expressed as follows:

$$
\frac{1}{q t}=\frac{1}{k_{2} q_{2}^{2}}+\frac{1}{q_{2}} t
$$

where $q_{2}$ is the maximum adsorption capacity $(\mathrm{mg} / \mathrm{g})$ for the pseudo-second-order adsorption, $\mathrm{q}_{\mathrm{t}}$ the amount of lead(II) ion adsorbed at equilibrium at time $\mathrm{t}(\mathrm{mg} / \mathrm{g})$ and $k_{2}$ is the equilibrium rate constant of pseudosecond-order adsorption $(\mathrm{g} / \mathrm{mg} / \mathrm{min})$. Values of $k_{2}$ and $q_{2}$ were calculated from the plot of $t / q t$ against $t$ (Figure 12). The correlation coefficients for the pseudo-second-order kinetic plots were very high 


\section{Available online at www.ijrat.org}

$\left(\mathrm{R}^{2}=0.997\right)$ (Table 2). The results suggested that the second-order kinetic model. adsorption system studied followed the pseudo-

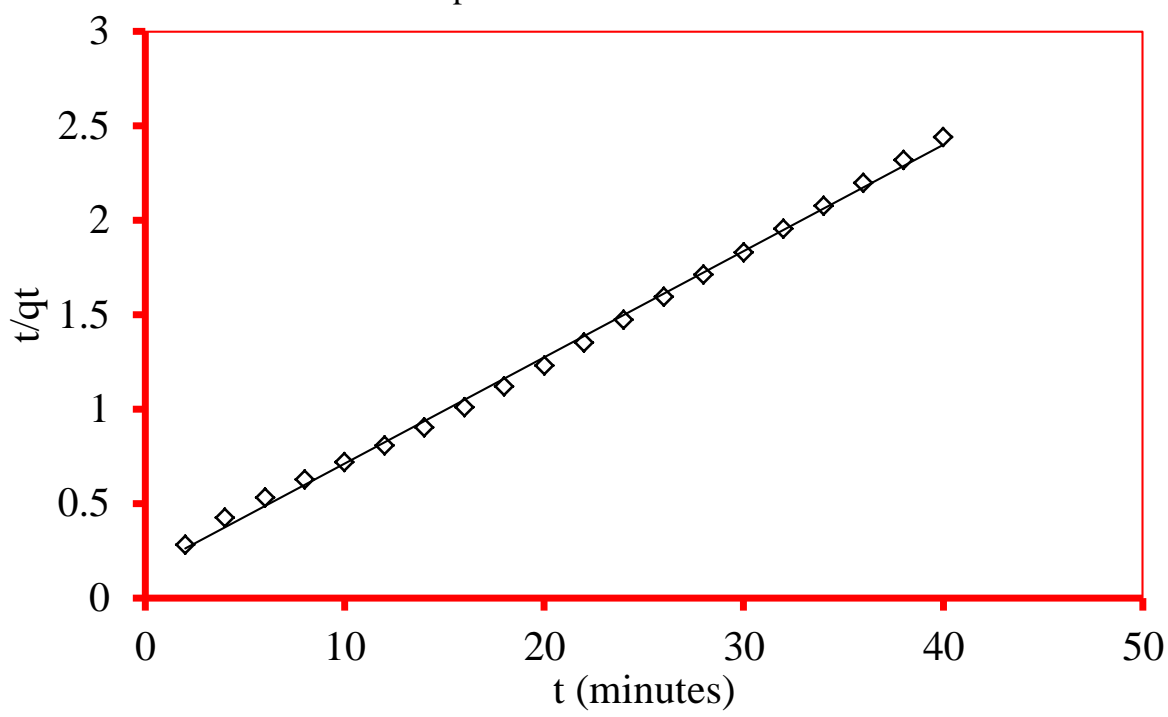

Figure 12: Pseudo-first-order plot for Lead (II) ion adsorption onto PPC.

3.6.3 Intra particle diffusion (Morris and Weber) model

The last applied alternative kinetic model in this study is intraparticle diffusion model [49]

$$
q_{t}=K_{a d} t^{1 / 2}+C
$$

The intraparticle diffusion model describes adsorption processes based on adsorbate $\left(\mathrm{Pb}^{2+}\right.$ ions) diffuses toward adsorbent (i.e., the process is diffusion controlled), as depicted by the above equation. The calculated values of $\mathrm{K}_{\mathrm{ad}}$ and $\mathrm{C}$ from the slope and intercept of $\mathrm{q}_{\mathrm{t}}$ versus Square root ' $t$ ' are reported in Table 2 and Figure 13. Intraparticle diffusion is the sole rate limiting step, when the plot of $\mathrm{q}_{\mathrm{t}}$ versus Square root ' $t$ ' passes through the origin and the value of $\mathrm{C}$ (in this case) is equal to zero. These phenomenon shows that the intraparticle diffusionmodelmay be the controlling factor in determining the adsorption kinetics. The distance of $\mathrm{R}^{2}$ values (Table 2) from unity for adsorption of lead on PPC indicates the nonapplicability of this model that rejects the ratelimiting step in the intraparticle diffusion process.

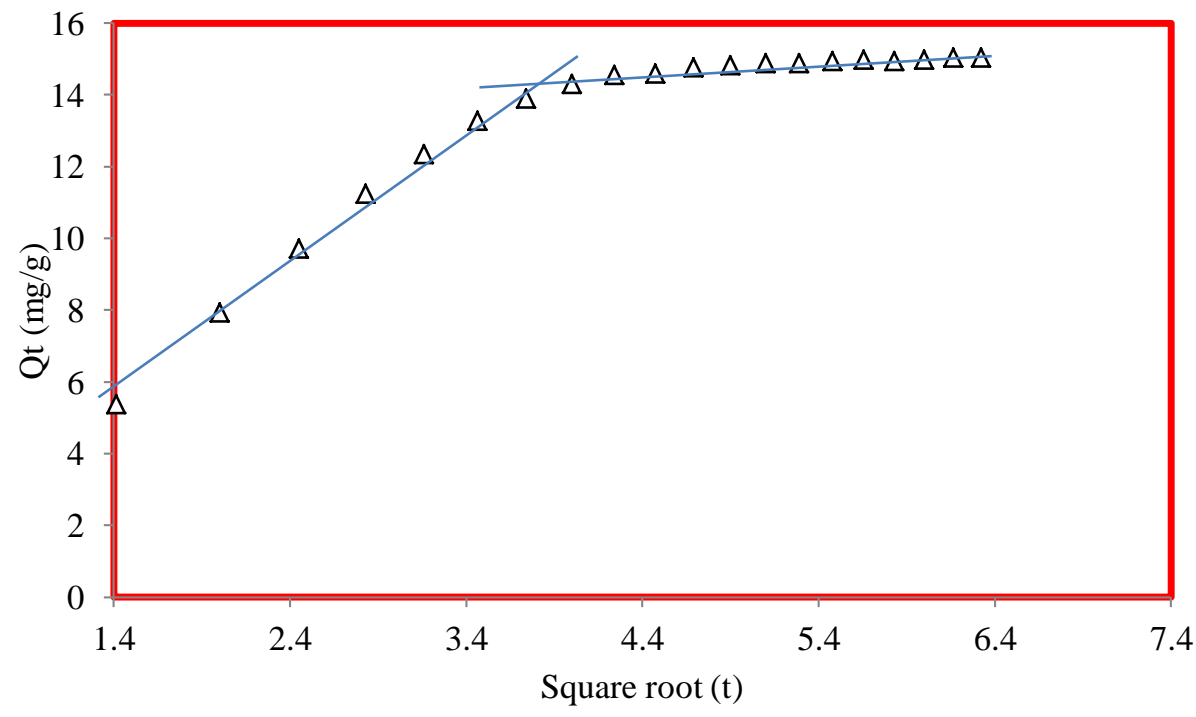

Figure 13: Intra particle diffusion plot for Lead (II) ion adsorption onto PPC. 


\section{E-ISSN: 2321-9637 \\ Available online at www.ijrat.org}

In order to test the applicability of the three different kinetic models, namely the Pseudo First order, the pseudo-second- order and the intraparticle diffusion model the experimental data were correlated with the linear forms of the three models respectively. The derived rate constants together with the correlation coefficient $\mathrm{R}^{2}$ for the $\mathrm{Pb}^{2+}$ ion adsorption system display the best-fitting results by the pseudo-secondorder rate equation $\left(\mathrm{R}^{2}=0.997\right)$, also shown in the figures are the experimental data. This indicates that the pseudo-second-order equation is potentially a generalized kinetic model for the current adsorption study.

\section{CONCLUSION}

The present work demonstrates the potential of the biomass as the starting materials as activated carbon. The results of this study show that it is feasible to prepare activated carbon with high surface area and pore volume from Pentapetes Phoenicea bio mass by direct chemical activation. Activation with $\mathrm{ZnCl}_{2}$ followed by $\mathrm{HNO}_{3}$ treatment produced activated carbon with better developed porosities and adsorption properties. From the large number of recent works reviewed here, it is observed that the mechanism and kinetics of adsorption of $\mathrm{Pb}^{2+}$ ion on activated carbon adsorbents derived from plant biomass depend on the chemical nature and surface prosperities of the carbon materials and the experimental conditions, viz., adsorbate ion concentration, $\mathrm{pH}$ and agitation time. In conclusion, the activated carbon yield from the agricultural residues (PPC) was acceptable by using the two step activation for the adsorption of Lead ion from aqueous media.

\section{[1] REFERENCES}

[2] Imamoglu M.,; and Tekir O.;(2008) "Removal of copper (II) and lead (II) ions from aqueous solutions by adsorption on activated carbon from a new precursor hazelnut husks," Desalination, 228 ( 1-3), pp. 108-113

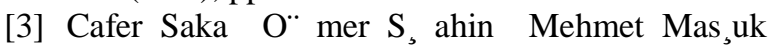

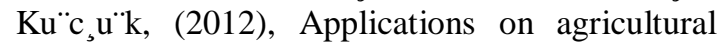
and forest waste adsorbents for the removal of lead (II) from contaminated waters, Int. J. Environ. Sci. Technol. 9, 379-394

[4] Kapoor A.; Viraraghavan T.; Cullimore DR (1999), Removal of heavy metals using the fungus Aspergillus niger. Bioresour Technol 70(1):95-104

[5] Lemraski E.G.; Sharafinia S.; (2016) Kinetics, equilibrium and thermodynamics studies of $\mathrm{Pb}^{2+}$ adsorption onto new activated carbon prepared from Persian mesquite grain, Journal of Molecular Liquids, 219, 482-492
[6] Kadirvelu K,; Goe J,; Rajagopal;; (2008). Sorption of lead, mercury and cadmium ions in multi- component system using carbon aerogel as adsorbent. Journal of Hazardous Materials 153,502-507,

[7] Tangjuank S,; Insuk N, ;Tontrakoon J,;Udeye V.; (2009) Adsorption of lead (II) and Cadmium (II) ions from aqueous solutions by adsorption on activated carbon prepared from cashew nut shells. World Academy of Science, Engineering and Technology 28:110-116

[8] Hua M.; Zhang S; Pan B.; Zhang W.; Lv L.; Zhang Q.; (2012), Heavy metal removal from water/wastewater by nanosized metal oxides: A review. Journal of Hazardous Materials 211, 317-331

[9] Mezohegyi, G.; . van der Zee, F. P.; Font J.; Fortuny A.; and Fabregat A.; (2012) "Towards advanced aqueous 102, pp. 148-164.

[10] RezaniaS.; Din. M. F. M.; Mohamad, S. E: Sohaili. J. Taib S. M.; Yusof, M. B. M.; Kamyab. H., Darajeh N., and Ahsan A;(2017) "Review on pretreatment methods and ethanol production from cellulosic water hyacinth," BioResources, 12(1), pp. 2108-2124

[11]El Qada, E. N.; Allen, S. J.; and Walker, G. M.; (2008) "Influence of preparation conditions on the characteristics of activated carbons produced in laboratory and pilot scale systems," Chem. Eng. J., vol. 142, pp. 1-13

[12] Malik, D. J.; Strelko Jr. V.; Streat, M.; and Puziy, A. M.; (2002) "Characterization of novel modified active carbons and marine algal biomass for the selective adsorption of lead," Water Research, vol. 36, no. 6, pp. 1527-1538

[13] Imamoglu M. and Tekir O., (2008) "Removal of copper (II) and lead (II) ions from aqueous solutions by adsorption on activated carbon from a new precursor hazelnut husks," Desalination, vol. 228, pp. 108-113

[14] Issabayeva, G. Aroua, M. K.; and Sulaiman, N. M. N.; (2006) "Removal of lead from aqueous solutions on palm shell activated carbon," Bioresource Technology, vol. 97, no. 18, pp. 2350-2355,

[15] Lalhruaitluanga H., Jayaram K., Prasad M. N. V., and Kumar K. K., (2010) "Lead(II) adsorption from aqueous solutions by raw and activated charcoals of Melocanna baccifera Roxburgh (bamboo) - a comparative study," Journal of Hazardous Materials, vol. 175, no. 1-3, pp. 311318

[16]Li Y., Du Q.; Wang X; et al., 2010 "Removal of lead from aqueous solution by activated carbon prepared from Enteromorpha prolifera by zinc chloride activation," Journal of Hazardous Materials, vol. 183, no. 1-3, pp. 583-589. 


\section{Available online at www.ijrat.org}

[17] Sekar M., Sakthi V., and Rengaraj S., "Kinetics and equilibrium adsorption study of lead(II) onto activated carbon prepared from coconut shell," Journal of Colloid and Interface Science, vol. 279, no. 2, pp. 307-313, 2004.

[18] Boudrahem, F. ; Aissani-Benissad, F. ; At-Amar, H. (2009), "Batch sorption dynamics and equilibrium for the removal of lead ions from aqueous phase using activated carbon developed from coffee residue activated with zinc chloride," Journal of Environmental Management, vol. 90, no. 10 , pp. 3031-3039,

[19] Acharya, J. ; Sahu, J. N. ; Mohanty, C. R.; Meikap, B. C.; (2009) "Removal of lead(II) from wastewater by activated carbon developed from Tamarind wood by zinc chloride activation," Chemical Engineering Journal, vol. 149, no. 1-3, pp. 249-262,

[20] Gupta, SS; Bhattacharyya, KG.; (2011) Kinetics of adsorption of metal ions on inorganic materials: a review, Advances in colloid and interface science 162 (1-2), 39-58

[21] Yuan G.; Seyama H.; Soma M.; Theng \& A. Tanaka B.K.G., .(1999). Adsorption of some heavy metals by natural zeolites : XPS and batch studies, J. Environ. Sci. Heal. A, 34:3, 625-648.

[22]Zielke, U. ; Huttinger, K.J. ; Hoffman, W.P. ; (1996) Surface-oxidized carbon fibers: I. Surface structure and chemistry, Carbon 34, 983-998

[23] Hu, Z.;. Srinivasan, M. P.; Ni, Y.; (2001) "Novel activation process for preparing highly microporous and mesoporous activated carbons," Carbon, vol. 39, pp. 877-886,

[24] McEnaney, B. ; (1987) "Estimation of the dimensions of micropores in active carbons using the Dubinin-Radushkevich equation," Carbon, vol. 25 , pp. $69-75$

[25] Boehm, H.P., 1994. Some aspects of the surface chemistry of carbon blacks and other carbons. Carbon 32, 759-769

[26] Yang K,; Peng J,; Xia H,; Zhang L; Srinivasakannan C; Guo S; (2010), Textural characteristics of activated carbon by single step $\mathrm{CO} 2$ activation from coconut shells. J Taiwan Inst Chem Eng;43:367-72.

[27] Salame, I.; Bagreev, A. ; Bandosz, T. J. (1999)"Revisiting the effect of surface chemistry on adsorption of water on activated carbons," Journal of Physical Chemistry B, vol. 103, pp. 3877-3884,

[28] Malee Tangsathitkulchai, Chaiyot Tangsa thitkulchai, Kamonchanok Wongsooksin, and Saowanee Chuyings akuntip (2012) Engineering Journal Volume 16 Issue 5, 29-43 DOI: 10.4186/ ej.2012.16.5.29.

[29] Puziy, A.M. Poddubnaya, O.I. Martínez-Alonso, A. Suárez-García F. and Tascón, J.M.D. (2003) Carbon, 41, 1181
[30] Puziy, A.M.; Poddubnaya, O.I. ; MartínezAlonso, A. Suárez-García F.; Tascón, J.M.D.; (2005), Carbon, 43, 2857

[31] Yu, C. Qiu, J.S. Sun, Y.F. Li, X.H. Chen G. and Zhao, Z.B. (2008) J. Porous Mater., 15, 151.

[32] Medikondu Kishore,et al(2014), Adsorption of Fluoride Ion on Activated Carbon Prepared from Delonix regia Dry Fruits, Asian Journal of Chemistry; Vol. 26, Supplementary Issue, S247S250

[33] Aktas Z. Activated carbons from various biomasses and characterisations. $8^{\text {th }}$ World Congress of Chemical Engineering (WCCE8) Montreal Canada 2009:1-6.

[34] Jenkins BM, Baxter LL, Miles Jr TR, Miles, TR.(1998), Combustion properties of biomass. Fuel Process Technol, 54:17-46.

[35] Cao X and Harris W (2010) Properties of dairymanure-derived biochar pertinent to its potential use in remediation. Bioresource Technology 101(14): 5222-5228

[36] Moreno-Castilla, C. ; Lopez-Ramon M.V. ; Carrasco-Marin, F. ;(2000) Carbon, 38, 1995

[37] Tarkovskaya, I. A., Shevchenko, S. I. and Chernenko, A. N. (1969) Ukrainskii Khinticheskii Z/wrnal Ukrainian Chemical Journal,35 (11), p. 1160.

[38] Strazhesko, D. N; and Bronshtein, V. N.; (1949), Ukrainskii Khimicheskii Zlturnal (Ukrainian Chemical Journal). 15(1), p. 53.

[39] CHAOUCH et al., (2014) Adsorption of Lead (II) from Aqueous Solutions onto Activated Carbon Prepared from Algerian Dates Stones of Phoenix dactylifera L (Ghars variety) by H3PO4 Activation Orient. J. Chem., Vol. 30(3), 13171322

[40] Kafia M.; Shareef Surchi,; (2011), Agricultural Wastes as Low Cost Adsorbents for Pb Removal: Kinetics, Equilibrium and Thermodynamics, International Journal of Chemistry, Vol. 3 (3), 103-112

[41] Chen, S. ; Zhang, J.; Zhang, C.; Yue Q.; Li, Y.; (2010), Equilibrium and kinetic studies of methyl orange and methyl violet adsorption on activated carbon derived from Phragmites australis, Desalination 252, 149-156.

[42] L. Erikssion, E. Johanssn, N. Kettaneh-Wold, J. Trygg. C. Wikström. S. Wold. Multi-and megavariate data analysis. $2^{\text {nd }}$ ed. Umetrics $A B$, 2000, ISBN 91-973730-0, 227 page

[43] L. Eriksson. E. Johansson. N. Kettaneh-Wold. C Wikström. S- Wold. Dasign of Experiments. $3^{\text {rd }}$ ed. Umetrics AB, 2006, ISBN 91-973730-0, 235 page

[44] Freundlich H.M.F.; (1906) , Z. Phys. Chem. 57, 385.

[45] Mehmet E.; Argun, Sukru Dursun, Celalettin Ozdemir, Mustafa Karatas. (2007). Heavy metal 
adsorption by modified oak sawdust: Thermodynamics and kinetics. J. Hazard. Mater. 141, 77-85.

[46] Langmuir, (1918), J. Am. Chem. Soc. 40, 1361

[47] Y.S. Ho, G. McKay. 1999. Pseudo-second order model for sorption processes. Process Biochem. 34, 451-465.

[48] Tutem E.; Apak R.; Unal, C.F.; (1998) Adsorptive removal of chlorophenols from water by bituminous shale, Water Res. 32, 2315-2324

[49] M. Sekar et al.; (2004) Kinetics and equilibrium adsorption study of lead(II) onto activated carbon prepared from coconut shell, Journal of Colloid and Interface Science 279, 307-313

[50] Ensieh Ghasemian Lemraski.; Soheila Sharafinia.; (2016) , Kinetics, equilibrium and thermodynamics studies of $\mathrm{Pb} 2+$ adsorption onto new activated carbon prepared from Persian mesquite grain Journal of Molecular Liquids 219 , 482-492 